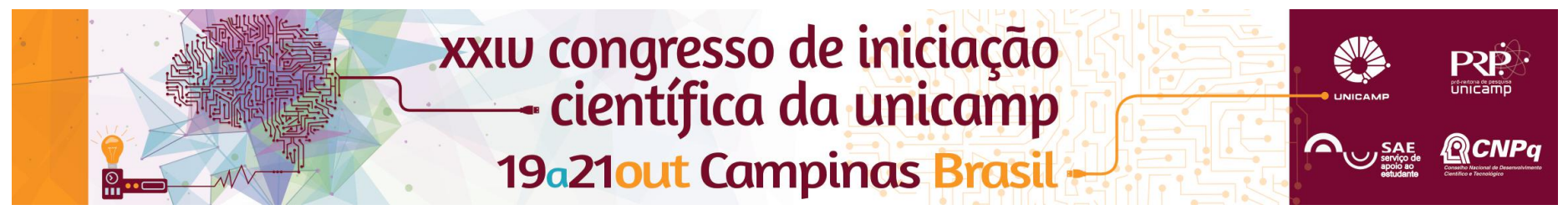

\title{
Relação entre depressão, ansiedade, estresse e personalidade.
}

\author{
Juliana B. Freire, Wagner L. Machado.
}

\section{Resumo}

Devido a prevalência dos sintomas de depressão, ansiedade e estresse nos brasileiros buscou-se elucidar com a ajuda dos instrumentos DASS- 21 (Depression Anxietry Stress Scale) e escala Breve (marcadores reduzidos para a avaliação da personalidade) a importância dos traços básicos da personalidade, investigados dentro do Modelo dos cinco Grande Fatores e sua relação e atuação com os fatores de risco ou proteção para os sintomas de depressão, ansiedade e estresse. Para a realização de tal foram utilizadas na investigação as relações de correlações bivariadas e a análise de rede, reponsável pela verificação em gráfico da influência e existência de relações causais entre variáveis, além de padrões individuais.

\section{Palavras-chave}

Análise de rede, depressão, personalidade.

\section{Introdução}

Ao longo dos tempos as relações entre as dimensões afetivas negativas têm sido consideradas importantes tanto a partir de um ponto de vista teórico quanto ao que se refere à saúde mental e, por isso, constituem dimensões relevantes na psicologia e na psicopatologia. Uma possibilidade de avaliar os estados afetivos negativos dentre os transtornos psquiátricos menores como a depressão, ansiedade e o estresse - seria através do instrumento desenvolvido por Lovibond \& Lovibond (1995) denominado Depression Anxiety and Stress Scale (DASS- 21). Dentro deste contexto, conhecer os traços da personalidade é de extrema relevância para que, assim, se possa estabelecer uma relação entre estes (HAUCK FILHO 2012).

O modelo dos Cinco Grande fatores (CGF) será, portanto, o responsável por representar os traços da personalidade (MACHADO, 2014). Assim, investigar as relações entre os traços de personalidade e os sintomas de estresses, depressão e ansiedade é fundamental para que, posteriormente, seja possível investigar a associação bivariada entre todos os tipos de traços de personalidade existentes e os sintomas de vunerabilidades (ansiedade, depressão e estresse).

\section{Resultados e Discussão}

$\mathrm{Na}$ análise de rede gLasso, pode-se observar que as linhas variam de cor, intensidade e espessura; tal fato é representado pela magnitude da associação que existem entre as variáveis. Assim, o posicionamento das variáveis na rede é fundamental porque as variáveis que mantém relações intensas sao mais atraídas entre si e a cor também. A cor verde representa uma relação positiva, ou seja, diretamente proporcional. Como no caso de Rel. e Soc. que representam os traços da personalidade de realização e socialização, conclui-se pela análise do gráfico que são diretamente proporcionais, onde quanto mais organizada, determinada e cuidadosa (realização) for uma pessoa ela tende a ser também uma pessoa mais compassiva e que exercerá a cooperação (socialização). Um importante destaque está voltado para o traço neuroticismo o qual faz correlação com a depressão, ansiedade e estresse.

Figura 1. Gráfico gLasso - Análise de rede.

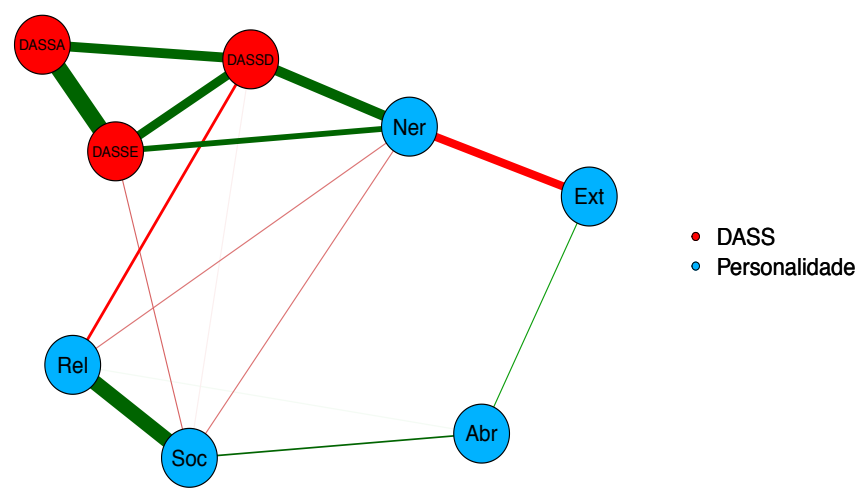

\section{Conclusões}

Foi observado que quanto mais relações com os demais nodos uma variável exercer, mais central tende a ser este nodo na analise de rede. Neste presente estudo foi o traço do neuroticismo, o nodo que exerceu relação em maior quantidade. A relevância da pesquisa relaciona-se ao conhecimento que visa entender melhor as vunerabilidades psicológicas para se obter assim, auxilio em programas preventivos.

\section{Agradecimentos}

Ao orientador Prof. Dr. Wagner de Lara Machado -

Pontifícia Universidade Católica Campinas - PUC.

Programa de Pós - Graduação em Psicologia.

Usar esse espaço para referências, seguindo o estilo indicado - Padrão ACS ou ABNT ou Vancouver (letra Times 8). Ex:

\footnotetext{
${ }^{1}$ Curtis, M. D.; Shiu, K.; Butler, W. M. e Huffmann, J. C. J. Am. Chem. Soc.
} 